\title{
KARAKTERISTIK UMUR PRODUK PADA MODEL WEIBULL
}

\author{
Sudarno \\ Staf Pengajar Program Studi Statistika FMIPA UNDIP
}

\begin{abstract}
Long life of product can reflect its quality. Generally, good products have long life. There are functions that relationship with life as reliability function, hazard rate function, mean time to failure, and mean residual life. In this writing those functions be used to product which has the failure time of a component is distributed Weibull. The reliability function is exponential function. For value $\theta$ is constant, the reliability value is decrease function, if $\gamma$ is greather with respect to time. Meanwhile hazard rate function could be monotone increase function, constant function, monotone decrease function, if doing by simulation with shape parameter by one. Really, the mean time to failure product hang on Weibull distribution parameters. But the mean residual life is reciprocal with respect to its reliability.
\end{abstract}

Keywords: Weibull Model, Reliability and Hazard Rate Functions, Mean Time to Failure, Mean Residual Life.

\section{Pendahuluan}

Suatu produk yang baik tentunya harus memperhatikan kharakteristik mutunya. Hal-hal yang berhubungan dengan mutu dapat berupa umur atau reliabilitas. Makin lama kemampuan hidup dari produk, dapat dikatakan bahwa mutunya semakin bagus. Peluang suatu produk untuk dapat hidup lebih dari waktu yang telah ditentukan disebut reliabilitas ${ }^{[1,3]}$. Setiap produk diharapkan mempunyai reliabilitas yang tinggi, agar produk tersebut disukai oleh konsumen. Reliabilitas berguna pula untuk menentukan waktu garansi. Dengan adanya waktu garansi baik produsen maupun konsumen sama-sama untung. Untuk menggambarkan intensitas peluang bahwa umur produk akan gagal pada waktu tertentu, merupakan tingkat risiko pada waktu tersebut. Nilai ini merupakan ramburambu untuk mengetahui tingkat bahaya atau kerugian yang mungkin muncul ${ }^{[6]}$.

Umur produk merupakan lamanya produk tersebut mampu berfungsi sampai tiba waktu kegagalannya. Sedangkan sisa umur produk merupakan lamanya produk masih berfungsi setelah waktu tertentu. Reliabilitas, umur dan sisa umur produk adalah saling berhubungan. Sehingga dapat dikatakan bahwa mereka merupakan ukuran reliabilitas produk $^{[1]}$. Ukuran-ukuran ini menyatakan kemampuan berfungsinya produk dari awal hingga muncul kegagalannya.

Tujuan dari pembahasan ini adalah ingin mengetahui fungsi reliabilitas dan tingkat risiko suatu produk. Selain itu, akan menaksir umur dan sisa umur produk, jika jumlah kegagalannya diasumsikan berdistribusi Weibull.

\section{Model Distribusi Weibull}

Model ini banyak dipergunakan untuk sebaran fungsinya berupa fungsi tidak linier terhadap waktu $t$. Fungsi padat peluang dari model distribusi Weibull adalah

$$
f(t)=\frac{\gamma}{\theta} t^{\gamma-1} e^{-\frac{t^{\gamma}}{\theta}}, \quad t>0
$$

dengan parameter $\theta$ dan $\gamma$ adalah bernilai positif. Parameter $\theta$ merupakan parameter skala merupakan karakteristik umur, yang menggambarkan sifat umur produk. Sedangkan parameter $\gamma$ merupakan parameter bentuk, yang menggambarkan macam-macam bentuk distribusinya, jika nilainya bervariabel. 
Jika nilai $\gamma$ dilakukan simulasi pada fungsi padat peluang Weibull, maka akan didapat distribusi seperti pada Tabel 1 berikut.

Tabel 1. Hasil Simulasi Nilai $\gamma$ terhadap Distribusi

\begin{tabular}{|c|c|c|}
\hline$\gamma$ & $f(t)$ & Distribusi \\
\hline 1 & $\frac{1}{\theta} e^{-\frac{t}{\theta}}$ & Eksponensial \\
\hline 2 & $\frac{2}{\theta} t e^{-\frac{t^{2}}{\theta}}$ & Rayleigh \\
\hline 3,43927 & $\frac{3,43927}{\theta} t^{2,43927} e^{-\frac{t^{3,43927}}{\theta}}$ & Normal $^{[2]}$ \\
\hline
\end{tabular}

Selanjutnya, fungsi distribusi kumulatif Weibull diberikan dengan:

$$
F(t)=\int_{0}^{t} \frac{\gamma}{\theta} \zeta^{\gamma-1} e^{-\frac{\zeta^{\gamma}}{\theta}} d \zeta=1-e^{-\frac{t^{\gamma}}{\theta}}, \quad t>0
$$

Fungsi reliabilitas Weibull adalah

$$
R(t)=e^{-\frac{t^{\gamma}}{\theta}}, \quad t>0
$$

Berikut ini disajikan plot dari fungsi reliabilitas Weibull untuk bermacam-macam nilai $\gamma$ (atau g), untuk suatu $\theta$ diambil konstan.

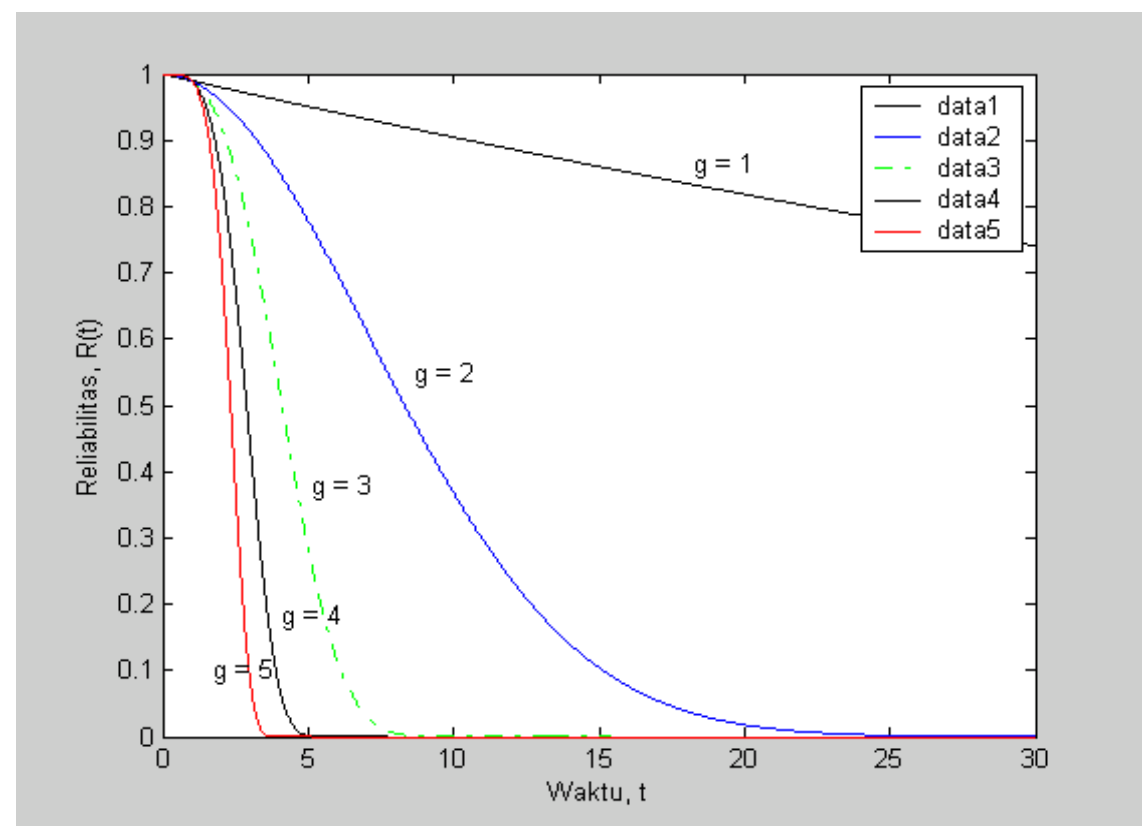

Gambar 1. Plot Fungsi Reliabilitas Weibull terhadap Waktu

Berdasarkan Gambar 1, diperoleh kesimpulan bahwa untuk nilai $\theta$ konstan, fungsi reliabilitasnya adalah makin kecil, jika nilai $\gamma$ makin besar terhadap waktu. Dapat pula dikatakan bahwa fungsi reliabilitas Weibull kurang sensitive untuk nilai $\gamma$ yang besar, dimana nilai $\theta$ dianggap konstan.

Juga, fungsi tingkat risiko Weibull diberikan dengan 


$$
h(t)=\frac{f(t)}{1-F(t)}=\frac{\gamma}{\theta} t^{\gamma-1}
$$

Jika dilakukan simulasi secara umum terhadap nilai $\gamma$ dengan $\theta$ dianggap konstan pada fungsi tingkat risiko Weibull didapat keputusan fungsi seperti pada Tabel 2 berikut ini.

Tabel 2. Hubungan antara $\gamma$ dengan Fungsi

\begin{tabular}{|c|c|}
\hline$\gamma$ & Fungsi \\
\hline Lebih dari 1 & Monoton naik \\
\hline Sama dengan 1 & Konstan \\
\hline Kurang dari 1 & Monoton turun \\
\hline
\end{tabular}

Di bawah ini ditampilkan plot dari fungsi tingkat risiko Weibull untuk suatu $\theta$ konstan dengan bermacam-macam nilai $\gamma$ (atau g).

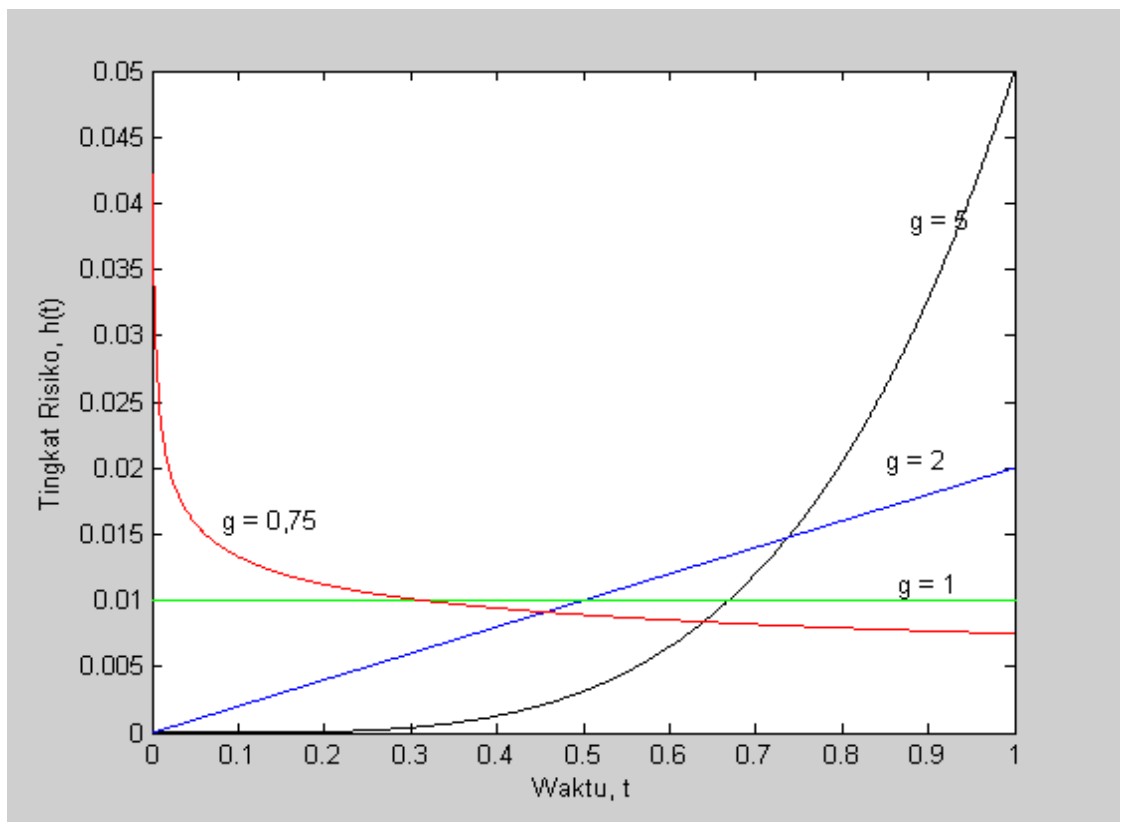

Gambar 2. Plot Fungsi Tingkat Risiko Weibull terhadap Waktu

Menurut Gambar 2, untuk nilai $\theta$ konstan dapat dikatakan bahwa pada $\gamma=1$, maka h(1) merupakan fungsi konstan. Sedangkan pada $\gamma$ lebih dari 1 , nilai awal $h(\gamma)$ lebih kecil dari $\mathrm{h}(1)$ tetapi akhirnya lebih besar darinya, yang mana makin besar nilai $\gamma$ nilai fungsi $\mathrm{h}(\gamma)$ akan cepat besar. Sebaliknya, pada $\gamma$ kurang dari 1 , nilai awal $h(\gamma)$ lebih besar dari $h(1)$ tetapi akhirnya lebih kecil darinya, yang mana makin kecil nilai $\gamma$ nilai fungsi $\mathrm{h}(\gamma)$ akan cepat mengecil.

Misalkan suatu produk diasumsikan bahwa waktu kegagalannya adalah berdistribusi Weibull dengan parameter $\theta=100$ dan $\gamma=5$. Maka reliabilitas untuk waktu sesudah $t$ adalah $R(t)=e^{-0,01 t^{5}}, \quad t>0$. Sehingga untuk $\mathrm{t}=1,5$ tahun didapat $\mathrm{R}(1,5)=0,9269$. Sedangkan tingkat risiko pada waktu $t$ adalah $h(t)=0,05 t^{4}$, pada $\mathrm{t}=1,5$ tahun tingkat risikonya adalah 0,2531 kegagalan per tahun. 


\section{Rataan Waktu Gagal dan Rataan Sisa Umur}

\subsection{Rataan Waktu Gagal}

Salah satu ukuran reliabilitas produk adalah mengetahui rataan waktu gagal. Rataan waktu gagal merupakan taksiran waktu antar dua kegagalan yang berturutan pada produk yang sekali pakai.

Misal terdapat $n$ produk yang sekali pakai dan diamati kapan waktu kegagalannya. Andaikan waktu kegagalannya masing-masing dinyatakan dengan $t_{1}, t_{2}, \ldots, t_{n}$. Taksiran rataan waktu gagal adalah $\frac{1}{n} \sum_{i=1}^{n} t_{i}$. Karena $t_{i}$ merupakan variabel acak, maka secara umum variabel acak ini dapat diganti dengan variabel acak T, yang menyatakan waktu kegagalan. Sehingga taksiran nilainya dapat dinyatakan dengan

$$
\mathrm{E}[\mathrm{T}]=\int_{0}^{\infty} t f(t) d t
$$

Telah diketahui bahwa $R(t)=1-F(t)$ dan $f(t)=\frac{d F(t)}{d t}=-\frac{d R(t)}{d t}$. Sehingga Persamaan (5) menjadi

$$
\mathrm{E}[\mathrm{T}]=-\int_{0}^{\infty} t d R(t)=\int_{0}^{\infty} R(t) d t
$$

karena $\mathrm{R}(\infty)=0$ dan $\mathrm{R}(0)=1$.

Selanjutnya menentukan rataan waktu gagal untuk distribusi Weibull. Berdasarkan Persamaan (3) dan (6), maka

$$
\mathrm{E}[\mathrm{T}]=\int_{0}^{\infty} e^{-\frac{t^{\gamma}}{\theta}} d t
$$

Dengan mensubstitusi $x=\frac{t^{\gamma}}{\theta}$, maka Persamaan (7) menjadi

$$
\mathrm{E}[\mathrm{T}]=\frac{\theta}{\gamma} \int_{0}^{\infty} e^{-x} \frac{1}{\theta^{1-\frac{1}{\gamma}}} x^{\frac{1}{\gamma}-1} d x=\frac{\theta^{\frac{1}{\gamma}}}{\gamma} \int_{0}^{\infty} e^{-x} x^{\frac{1}{\gamma}-1} d x=\theta^{\frac{1}{\gamma}} \Gamma\left(1+\frac{1}{\gamma}\right) .
$$

yang dapat dipergunakan untuk menetukan umur produk.

Sedangkan ragam waktu gagal dari distribusi Weibull yaitu

$$
\operatorname{Var}[\mathrm{T}]=\theta^{\frac{2}{\gamma}}\left\{\Gamma\left(1+\frac{2}{\gamma}\right)-\left[\Gamma\left(1+\frac{1}{\gamma}\right)\right]^{2}\right\}
$$

dengan $\Gamma(n)$ merupakan fungsi gamma, yaitu

$$
\Gamma(n)=\int_{0}^{\infty} x^{n-1} e^{-x} d x \operatorname{dan} \int_{0}^{\infty} x^{n-1} e^{-x / \theta} d x=\Gamma(n) \theta^{n} .
$$

Misal suatu produk diasumsikan bahwa waktu kegagalannya adalah berdistribusi Weibull dengan parameter $\theta=100$ dan $\gamma=5$. Maka taksiran umur produk dapat dicari menggunakan rataan waktu gagal, yaitu $100^{0,05} \Gamma(1,005)=1,2256$ tahun. Ragamnya adalah $100^{0,4}\left\{\Gamma(1,4)-[\Gamma(1,2)]^{2}\right\}=0,2791$. Oleh karena itu simpangan bakunya adalah 0,5283 tahun.

\subsection{Rataan Sisa Umur}

Ukuran karakteristik reliabilitas dari produk yang lain adalah fungsi rataan sisa umur L(t). Fungsi ini didefinisikan sebagai berikut:

$$
L(t)=E[T-t \mid T \geq t], \quad t \geq 0 .
$$


Maka fungsi rataan sisa umur adalah taksiran sisa umur, $T-t$, yang diberikan produk yang telah hidup sampai waktu $t$.

Jika fungsi densitas peluang bersyarat untuk sembarang waktu $\tau \geq t$ adalah

$$
f_{T \mid T \geq t}(\tau)=\frac{f(\tau)}{R(t)}, \quad \tau \geq t .
$$

Maka ekspektasi bersyarat dari fungsi yang diberikan dalam Persamaan (11) adalah

$$
E[T \mid T \geq t]=\int_{t}^{\infty} \tau f_{T \mid T \geq t}(\tau) d \tau=\int_{t}^{\infty} \tau \frac{f(\tau)}{R(t)} d \tau .
$$

Berdasarkan Persamaan (10), (11), dan (12), diperoleh rataan sisa umur berikut ini

$$
L(t)=\int_{t}^{\infty}(\tau-t) \frac{f(\tau)}{R(t)} d \tau=\frac{1}{R(t)} \int_{t}^{\infty} \tau f(\tau) d \tau-t
$$

karena $R(t)=\int_{t}^{\infty} f(\tau) d \tau$

Andaikan suatu produk dianggap bahwa waktu kegagalannya adalah berdistribusi Weibull dengan parameter $\theta=100$ dan $\gamma=5$. Maka akan mempunyai fungsi densitas peluang $f(t)=0,05 t^{4} e^{-0,01 t^{5}}, \quad t>0$. Sehingga didapat fungsi distribusi kumulatifnya $F(t)=1-e^{-0,01 t^{5}}$. Karena $R(t)=1-F(t)$, maka reliabilitas untuk waktu sesudah $t$ adalah $R(t)=e^{-0,01 t^{5}}$. Sedangkan tingkat risiko pada waktu $t$ adalah $h(t)=0,05 t^{4}$. Jika produk telah hidup selama 1,5 tahun atau 18 bulan, maka diperoleh $\mathrm{R}(1,5)=0,9269$.

Sehingga rataan sisa umur produk tersebut adalah

$$
L(1,5)=\frac{0,05}{0,9269} \int_{1,5}^{\infty} t^{5} e^{-0,01 t^{5}} d t-1,5=0,8927 \text { tahun. }
$$

Jadi taksiran sisa umur produk tersebut adalah kira-kira 10,7 bulan lagi baru mati.

Gambar untuk sebaran fungsi dari karakteristik produk pembahasan di atas, diberikan di bawah ini.

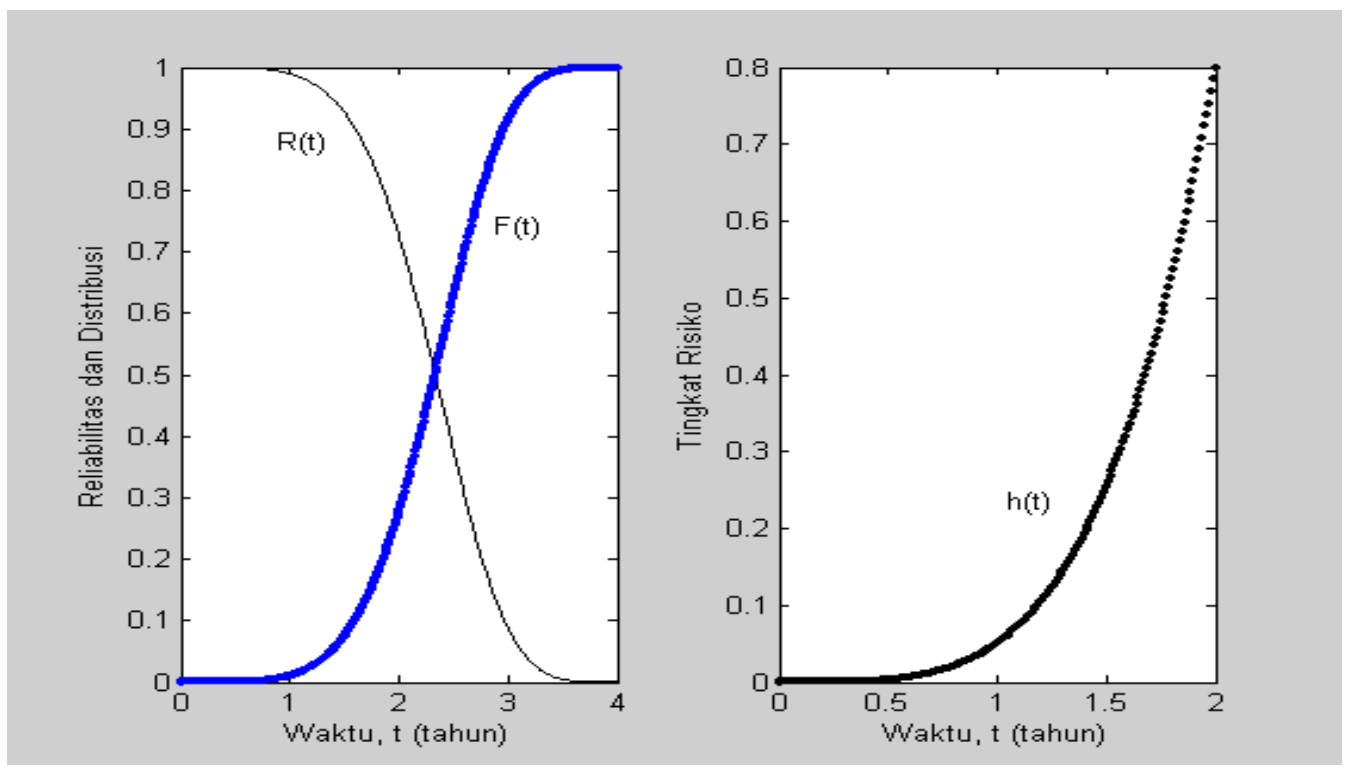

Gambar 3. Plot Fungsi Reliabilitas, Distribusi dan Tingkat Risiko Weibull terhadap Waktu

Menurut Gambar 3, untuk parameter $\theta$ dan $\gamma$ konstan dapat disimpulkan bahwa untuk perubahan waktu yang semakin besar, fungsi reliabilitasnya nilainya akan semakin 
kecil, pada kira-kira 3,5 tahun reliabilitasnya sudah bernilai nol. Sedangkan pada fungsi distribusi dan tingkat risiko dengan bertambahnya waktu, nilainya akan semakin bertambah besar. Setelah lebih dari setengah tahun baru muncul resiko kegagalan.

\section{Kesimpulan}

Model Weibull dapat dipergunakan untuk memprediksi waktu kegagalan yang sebarannya bercorak tidak linier. Dengan melakukan simulasi untuk nilai parameter bentuk tertentu, dapat dihasilkan distribusi eksponensial, Rayleigh, atau bahkan normal.

Untuk niliai $\theta$ konstan, fungsi reliabilitasnya adalah makin kecil, jika nilai $\gamma$ makin besar terhadap waktu. Tetapi, pada $\gamma=1$, maka fungsi tingkat risikonya merupakan fungsi konstan. Sedangkan pada $\gamma$ lebih dari 1, fungsi tingkat risikonya merupakan fungsi monoton naik dan pada $\gamma$ kurang dari 1, fungsi tingkat risikonya merupakan fungsi monoton turun.

Rataan waktu gagal adalah bergantung pada parameternya. Sedangkan rataan sisa umur berbanding terbalik terhadap reliabilitasnya.

\section{DAFTAR PUSTAKA}

1. Elsayed, E.A., Reliability Engineering, Addison Wesley Longman, Inc., Massachusetts, 1996.

2. Makino, T., Mean Hazard Rate and Its Application to the Normal Approximation of the Weibull Distribution, Naval Research Logistics Quarterly, 1984.

3. Mitra, A., Fundamentals of Quality Control and Improvement, Macmillan Publishing Company, 1993.

4. Moore, H., MATLAB for Engineers, Pearson Prentice Hall, Inc., New Jersey, 2007.

5. Ross, S.M., Introduction to Probability Models, Sixth Edition, Academic Press, New York, 1997.

6. Ross, S.M., Stochastic Processes, Second Edition, John Wiley \& Sons, Inc., New York, 1996. 